\title{
PENGARUH MASSA KATALIS DAN WAKTU REAKSI PADA PEMBUATAN BIODIESEL DARI LIMBAH MINYAK JELANTAH DENGAN MENGGUNAKAN KATALIS HETEROGEN $\mathrm{K}_{2} \mathrm{O}$ DARI LIMBAH KULIT KAKAO
}

\section{EFFECT OF CATALYST MASS AND REACTION TIME ON BIODIESEL PRODUCTION FROM WASTE COOKING OIL USING HETERONEGEOUS CATALYST $\mathrm{K}_{2} O$ FROM WASTE COCOA PEEL ASH}

\author{
Jefry R Turnip, Trio F. L. Tarigan, Mersi Suriani Sinaga \\ Departemen Teknik Kimia, Fakultas Teknik, Universitas Sumatera Utara \\ Jl. Almamater Kampus USU Medan 20155, Indonesia \\ Email: jefryreyaldi11@gmail.com
}

\begin{abstract}
Abstrak
Minyak jelantah merupakan minyak limbah yang berasal dari jenis - jenis minyak goreng seperti halnya minyak jagung, minyak sayur, dan sebagainya. Tujuan dari penelitian ini adalah pemanfaatan limbah minyak jelantah sebagai bahan baku untuk membentuk biodiesel dengan $\mathrm{K}_{2} \mathrm{O}$ sebagai katalis padat dari limbah kulit kakao yang dikalsinasi dengan temperatur $650^{\circ} \mathrm{C}$ selama 4 jam. Minyak ini mengandung kadar Free Fatty Acid (FFA) yang tinggi yaitu 3,13\%. Maka pretreatment perlu dilakukan menggunakan karbon aktif $(1 \%$ b/b) untuk menurunkan kadar FFA. Pada penelitian ini akan mengamati pengaruh waktu reaksi dan massa katalis. Karakteristik biodiesel dianalisa meliputi kadar metil ester, densitas, dan viskositas berdasarkan Standard Nasional Inbdponesia (SNI). Kondisi terbaik diperoleh dengan jumlah katalis $6 \%(b / b)$ yang dikalsinasi pada $650{ }^{\circ} \mathrm{C}$, waktu reaksi 180 menit, rasio mol alkohol dan minyak jelantah adalah $12: 1$ dan suhu reaksi $65^{\circ} \mathrm{C}$, sehingga kemurnian dan yield biodiesel adalah 99,58 \% dan 92,68 \% setelah dilakukan pencucian biodiesel hingga jernih dan bening. Hasil peneltian ini menunjukkan minyak jelantah merupakan bahan baku yang layak dalam pembuatan biodiesel.
\end{abstract}

Kata kunci : Biodiesel, Kulit Kakao, Minyak Jelantah, Pretreatment, Transesterifikasi

\begin{abstract}
Waste cooking oil is a waste oil that comes from many types of cooking oils such as corn oil, vegetable oil, ect. The purpose of this research is to waste cooking oil as a raw material to form biodiesel with $\mathrm{K}_{2} \mathrm{O}$ as the solid catalyst from cocoa pod ash (CPA) which is calcined on temperature $650{ }^{\circ} \mathrm{C}$ within 4 hours. This oil contains a high level of Free Fatty Acid (FFA) that is 3.13\%. Therefore, pretreatment should be done by using activated carbon $(1 \% \mathrm{w} / \mathrm{w})$ to reduce levels of FFA. The research will be observed the effect of reaction time and the mass of catalyst. The characteristics of biodiesel is analyzed according to the levels of methyl ester in biodiesel, density, and viscosity based on the Indonesian National Standard (SNI). The best conditions of biodiesel are obtained with the amount of catalyst is $6 \%(\mathrm{w} / \mathrm{w})$ that is calcined at $650{ }^{\circ} \mathrm{C}$, reaction time 180 minutes, ratio mol of alcohol: oil is 12: 1, and $65^{\circ} \mathrm{C}$ reaction of temperature, resulting the purity and yield of biodiesel is $99,8 \%$ and $92,68 \%$. The results of this research indicates that the use of waste cooking as a raw material is suitable in the manufacture of biodiesel.
\end{abstract}

Keywords: Biodiesel, Cocoa pod husks, WCO, Pretreatment, Transesterification.

\section{Pendahuluan}

Peningkatan pertumbuhan ekonomi global menyebabkan permintaan bahan bakar meningkat sehingga ketersediaan bahan bakar fosil menipis. Selain itu, penggunaan bahan bakar fosil mengakibatkan bahaya lingkungan seperti emisi gas rumah kaca dan polutan. Jadi hal ini sangat mendesak untuk menemukan sumber energi yang bersih dan terbarukan untuk menggantikan bahan bakar fosil [18].

Biodiesel adalah alkil ester dari rantai panjang asam lemak yang berasal bahan berlemak, seperti minyak nabati atau lemak hewani [16]. Minyak jelantah (waste cooking oil / WCO) adalah minyak limbah yang bisa berasal dari jenis-jenis minyak goreng seperti halnya minyak jagung, minyak sayur, minyak samin dan sebagainya [12].

Metode yang sering digunakan untuk produksi biodiesel adalah proses transesterifikasi. Reaksi transesterifikasi merupakan reaksi antara trigliserida dengan alkohol yang mana bertujuan untuk mengubah asam - asam lemak dari trigliserida kedalam 
bentuk ester yaitu metil ester asam lemak [15]. Alkohol yang biasanya digunakan pada reaksi transesterifikasi biodiesel adalah metanol, etanol, propanol, butanol, dan amil alkohol [9]. Metanol secara umum telah digunakan sebagai pelarut dan agen esterifikasi dalam pembuatan biodiesel dibawah kondisi supercritical karena sifatnya yang memiliki titik didih rendah dan tekanan yang rendah pula [17]. Biodiesel umumnya diproduksi secara transesterifikasi minyak nabati atau lemak hewan dengan alkohol seperti metanol atau etanol dengan adanya katalis asam atau katalis alkali [13]. Katalis alkali yang biasa di pakai yaitu $\mathrm{CaO}$ dan $\mathrm{K}_{2} \mathrm{O}$. Seperti yang dilakukan Sinaga et all, metil ester dihasilkan dari Crude Palm Oil dengan katalis $\mathrm{CaO}$ yang berasal dari tulang ayam [7]. Dalam penelitian ini, digunakan katalis heterogen kulit kakao. Kulit kakao (Cocoa Pod Husk / CPH) adalah limbah pertanian utama dari industri kakao dan telah ditemukan untuk menjadi sumber yang kaya kalium karbonat $\left(\mathrm{K}_{2} \mathrm{CO}_{3}\right)$. Sementara itu, Kalium dari abu kulit kakao merupakan sumber potensi tinggi sebagai katalis untuk produksi biodiesel karena dapat diperbaharui dan ramah lingkungan sehingga, dalam penelitian ini digunakan sebagai katalis heterogen untuk transesterifikasi [2]. .

\section{Teori}

Minyak Goreng Bekas / Jelantah

Minyak jelantah adalah minyak limbah yang bisa berasal dari jenis-jenis minyak goreng seperti halnya minyak jagung, minyak sayur, minyak samin dan sebagainya. Minyak ini biasanya merupakan minyak bekas pemakaian kebutuhan rumah tangga, umumnya dapat digunakan kembali untuk keperluan kuliner [5]. Pada umumnya minyak goreng bekas mengandung senyawa - senyawa antara lain: polimer, aldehida, asam lemak, senyawa aromatik dan lakton. Minyak goreng bekas tersebut tidak baik untuk kesehatan apabila kandungan senyawa polar mencapai $25-27 \%$ karena dapat memperbesar hati, ginjal, jantung dan bersifat karsinogenik [4].

Minyak goreng bekas merupakan salah satu bahan baku yang memiliki peluang untuk pembuatan biodiesel, karena minyak ini masih mengandung trigliserida, di samping asam lemak bebas [3]. Dari sejumlah pengujian awal yang dilakukan, diperoleh bahwa biodiesel hasil dari minyak jelantah ini dapat digunakan sebagai substitusi langsung minyak solar dengan pengurangan performa yang tidak signifikan, hanya $5-7 \quad \%$ terhadap daya dan torsi pada putaran maksimum [9]. Pretreatment minyak jelantah dilakukan dengan menggunakan karbon aktif. Putra, dkk [11] melaporkan bahwa proses pretreatment minyak jelantah dengan karbon aktif $10 \%(\mathrm{~b} / \mathrm{b})$ dapat menurunkan secara signifikan kadar air menjadi $<0,1 \%$ dan FFA (Free Fatty Acid) menjadi 0,23\%.

\section{Biodiesel}

Biodiesel merupakan bahan bakar alternatif yang ramah lingkungan karena diproduksi dari sumber daya alam. Biodiesel umumnya diproduksi secara transesterifikasi minyak nabati atau lemak hewan dengan alkohol seperti metanol atau etanol dengan adanya katalis asam atau katalis alkali [13]. Biodiesel yang merupakan pengganti bahan bakar, terbuat dari monoalkil ester rantai panjang asam lemak yang disiapkan dari minyak sayuran terbarukan atau lemak hewan, telah mampu menjadi pertimbangan menarik sebagai sebuah bahan bakar terbarukan alternatif untuk mesin diesel [1].

\section{Katalis Kulit Kakao}

Adanya katalis dapat membantu dalam reaksi transesterifikasi [12]. Katalis yang digunakan yaitu kulit kakao $\left(\mathrm{K}_{2} \mathrm{CO}_{3}\right)$. Kulit kakao adalah limbah pertanian dari industri kakao yang kaya kalium karbonat $\left(\mathrm{K}_{2} \mathrm{CO}_{3}\right)$. $\mathrm{K}_{2} \mathrm{CO}_{3}$ dari abu $\mathrm{CPH}$ dianalisis mengandung sekitar $142 \mathrm{mg} / \mathrm{g}$ karbonat, 3,7 mg / g nitrat, $1,23 \mathrm{mg} / \mathrm{g}$ fosfat dan beberapa jejak silikat dan sulfat. Kalium dari kulit kakao memiliki potensi sebagai sumber katalis basa heterogen, dimana kulit kakao merupakan terbarukan dan ramah lingkungan untuk produksi biodiesel berkelanjutan [2]. Pada treatment kalsinasi dari katalis ini di karenakan untuk mendekomposisi dari potassium karbonat [10] seperti reaksi berikut :

$$
\mathrm{K}_{2} \mathrm{CO}_{3} \rightarrow \mathrm{K}_{2} \mathrm{O}+\mathrm{CO}_{2}
$$

\section{Metanol}

Alkohol yang paling umum digunakan adalah metanol karena memiliki berat molekul paling rendah sehingga kebutuhan untuk proses transesterifikasi relatif sedikit, harganya lebih murah, daya reaksinya lebih tinggi dan lebih stabil dibandingkan dengan alkohol berantai panjang [8].

Metanol juga merupakan bentuk alkohol yang paling sederhana, cairan yang mudah menguap, tidak berwarna dengan bau yang khas. Metanol dapat digunakan sebagai bahan pendingin anti beku, pelarut, bahan bakar dan sebagai bahan additif bagi etanol industri. Metanol diproduksi alami oleh metabolisme anaerobik oleh bakteri [6]. 


\section{Metode \\ Bahan dan Peralatan}

Bahan baku yang digunakan pada penelitian ini adalah minyak jelantah, metanol dan kulit kakao sebagai katalis. Peralatan yang digunakan adalah hot plate, furnace, timbangan digital, viskosimeter ostwald, ball mill, and oven. Penelitian dilakukan dengan variasi persen katalis $4 \%, 5 \%$, dan $6 \%$ dan variasi waktu 2 jam, 3 jam, dan 4 jam dengan rasio molar metanol : minyak 12:1 dengan putaran $500 \mathrm{rpm}$. Bahan baku minyak jelantah dan biodiesel akan dilakukan analisa dengan alat Gas Chromatography (GC) type Shimadzu QP 2010 Brands.

\section{Prosedur Kerja \\ Tahap Preparasi Abu Kulit Buah Kakao}

Kulit buah kakao dikalsinasi dalam furnace dengan variasi temperatur pembakaran $650{ }^{\circ} \mathrm{C}$ selama 4 jam hingga menjadi abu. Penentuan Kadar kalium dalam abu kulit kakao di analisa dengan spektrfotometer serapan atom (AAS)

\section{Proses pretreatment Bahan Baku Minyak Goreng Bekas \\ Langkah-langkah dalam pretreatment} minyak jelantah yaitu pertama dilakukan penyaringan bahan baku WCO dengan kertas saring Whatman no. 41, minyak jelantah ditampung dan didiamkan selama beberapa hari kemudian bahan baku ditimbang, Terbentuk dua lapisan emulsi minyak-air. Emulsi minyak - air dipanaskan selama \pm 30 menit pada suhu 110 ${ }^{\circ} \mathrm{C}$ untuk menghilangkan kandungan air dengan menggunakan hot plate .

\section{Analisa Kadar FFA dengan Metode AOCS ca5a-40}

Sebanyak 20 g sampel WCO dimasukkan ke dalam labu erlenmeyer kemudian di tambahkan $150 \mathrm{ml}$ etanol 95\% (v/v). Campuran dikocok kuat hingga sampel larut dan diambil sebanyak $10 \mathrm{ml}$. Ditambahkan 3 tetes indikator phenolphtalein (10 g/l dalam 95\% etanol) lalu dititrasi dengan $\mathrm{NaOH} 0,1 \mathrm{~N}$ hingga berubah dari bening menjadi merah rosa. Dicatat volume $\mathrm{NaOH}$ 0,1 N yang terpakai [16].

\section{Proses Penurunan Kadar FFA Minyak Jelantah (Waste Cooking Oil)}

Prosedur penurunan kadar FFA ini dilakukan dengan mengadopsi prosedur yang dilakukan oleh Putra, dkk [11] dengan beberapa modifikasi: minyak jelantah (WCO) disaring dengan kertas saring untuk menghilangkan zat pengotor, kemudian ditimbang sebanyak $50 \mathrm{~g}$ dan dipanaskan hingga suhu $110{ }^{\circ} \mathrm{C}$, dimasukkan sebanyak 0,5 g karbon aktif (1\% b/b) dan kemudian diaduk selama 80 menit. Campuran disaring dan dilakukan prosedur analisa kadar FFA, apabila kadar FFA didapat < $1 \%$, maka dilanjutkan ke proses transesterifikasi.

\section{Proses Transesterifikasi}

Ditimbang abu kulit kakao sebanyak 6\% (b/b) lalu dimasukkan kedalam beaker glass dan ditambahkan metanol hingga sesuai dengan rasio molar metanol/WCO 9:1 kedalam beaker glass lalu didiamkan 24 jam. Sejumlah WCO dimasukan dengan metanol dengan rasio molar yang telah ditentukan dari metanol terhadap WCO kedalam labu leher tiga yang dilengkapi dengan pendingin refluk, termometer dan magnetic stirrer diatas hot plate. Dimasukkan abu kulit kakao dengan berat tertentu dari berat total WCO dan metanol kedalam campuran didalam labu leher tiga. Dipanaskan campuran dengan hot plate hingga mencapai suhu reaksi konstan sebesar $65^{\circ} \mathrm{C}$, dihomogenkan campuran menggunakan magnetic stirrer dengan kecepatan 500 rpm selama waktu tertentu.

Dipisahkan lapisan bawah yang merupakan campuran katalis abu kulit kakao, metanol dan gliserol dengan menggunakan pompa vakum. Dimasukkan campuran reaksi kedalam corong pemisah dan dibiarkan hingga terbentuk 2 lapisan. Ditambahkan air panas kedalam corong pemisah yang berisi lapisan atas dan dikocok untuk mengekstrak pengotor yang masih terdapat dalam lapisan ini, sehingga terbentuk kembali 2 lapisan. Dibuang kembali lapisan bawah dan perlakuan ini diulang beberapa kali hingga air cucian berwarna bening. Dikeringkan biodiesel dengan oven untuk mengurangi kadar air. Hasil yang diperoleh kemudian di analisa secara kuantitatif dan kualitatif yaitu analisa yield, kemurnian, densitas dan viskositas sesuai dengan Standar Nasional Indonesia (SNI 04-7182-2012) yang ditunjukan pada tabel 1 berikut :

Tabel 1. Persyaratan Kualitas Biodiesel [14]

\begin{tabular}{|l|l|}
\hline \multicolumn{1}{|c|}{ Parameter dan Satuannya } & \multicolumn{1}{c|}{ Batas Nilai } \\
\hline Kemurnian $(\%)$ & $>96$ \\
\hline $\begin{array}{l}\text { densitas biodiesel pada suhu } 40 \\
{ }^{\circ} \mathrm{C}\left(\mathrm{kg} / \mathrm{m}^{3}\right)\end{array}$ & $850-890$ \\
\hline $\begin{array}{l}\text { Viskositas kinematik pada } 40 \\
{ }^{\circ} \mathrm{C}, \mathrm{mm}^{2} / \mathrm{s}(\mathrm{cSt})\end{array}$ & $2,3-6,0$ \\
\hline
\end{tabular}

\section{Hasil}

Bahan baku WCO ini dianalisis dengan menggunakan GC untuk mengetahui komposisi asam-asam lemak yang terkandung didalamnya 
dan untuk menghitung berat molekul WCO (dalam bentuk trigliserida). Komposisi asam lemak WCO tersebut dapat dilihat pada tabel 2.

Tabel 2. Komposisi Asam Lemak dari WCO

\begin{tabular}{clc}
\hline $\begin{array}{c}\text { Retention Time } \\
\text { (menit) }\end{array}$ & Komponen Penyusun & $\begin{array}{c}\text { Komposisi \% } \\
(\mathrm{b} / \mathrm{b})\end{array}$ \\
\hline 2,635 & Asam Dekanoat $\left(\mathrm{C}_{10: 0}\right)$ & 0,0777 \\
5,368 & Asam Laurat $\left(\mathrm{C}_{12: 0}\right)$ & 0,3935 \\
8,196 & Asam Miristat $\left(\mathrm{C}_{14: 0}\right)$ & 0,9550 \\
11,178 & Asam Palmitat $\left(\mathrm{C}_{16: 0}\right)$ & 41,0134 \\
11,465 & Asam Palmitoleat $\left(\mathrm{C}_{16: 1}\right)$ & 0,2126 \\
13,670 & Asam Stearat $\left(\mathrm{C}_{18: 0}\right)$ & 3,9562 \\
14,011 & Asam Oleat $\left(\mathrm{C}_{18: 1}\right)$ & 44,1591 \\
14,512 & Asam Linoleat $\left(\mathrm{C}_{18: 2}\right)$ & 8,7113 \\
14,933 & Asam Linolenat $\left(\mathrm{C}_{18: 3}\right)$ & 0,0189 \\
15,920 & Asam Arakidat $\left(\mathrm{C}_{20: 0}\right)$ & 0,3465 \\
16,113 & Asam Eikosenoat $\left(\mathrm{C}_{20: 1}\right)$ & 0,1559 \\
\hline
\end{tabular}

Berdasarkan hasil analisis GC, komposisi asam lemak dari WCO dapat dilihat pada table diatas. Dari perhitungan, maka diperoleh berat molekul rata rata FFA WCO adalah 270,005 gr/mol dan berat molekul rata rata WCO (dalam bentuk trigliserida) adalah 848,1908 gr/mol. Dari hasil analisa kromatografi gas diperoleh kandungan asam lemak jenuh pada sampel minyak jelantah adalah $46,725 \%$ dan asam lemak tidak jenuh sebesar 53,257

FFA yang terdapat pada WCO sebelum pretreatment adalah $3,13 \%$ dan setelah pretreatment WCO dengan karbon aktif asam lemak bebas diperoleh $0,82 \%$ (telah $<1 \%)$.

Pengaruh Waktu Reaksi dan Persen Katalis Terhadap Yield Biodiesel

Hubungan pengaruh waktu reaksi dan persen katalis terhadap yield biodiesel dapat dilihat pada gambar 1 .

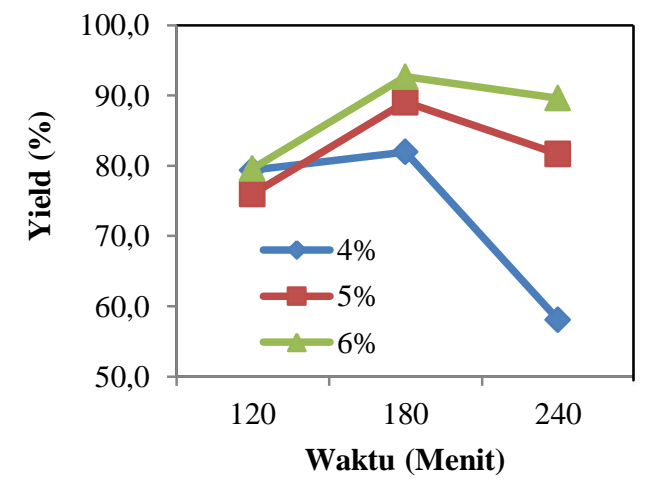

Gambar 1. Hubungan antara Waktu Reaksi dan Persen Katalis terhadap Yield Biodiesel
Pada gambar 1 dapat dilihat bahwa semakin lama waktu reaksi maka yield yang dihasilkan semakin banyak dan apabila waktu reaksi terlalu lama maka yield akan berkurang. Seperti yang ditunjukkan pada gambar 1 pada persen katalis $6 \%$ pada waktu 120 menit didapatkan yield sebesar $79,61 \%$ dan meningkat pada waktu reaksi 180 menit yaitu sebesar 92,68 dan menurun pada waktu 240 menit. Perhitungan yield dengan menggunakan persamaan sebagai berikut :

yield $=\frac{\text { massa biodiesel }}{\text { massa bahan baku }} \times$ kemurnian

Pengaruh Waktu Reaksi dan Persen Katalis Terhadap Kemurnian Biodiesel

Hubungan pengaruh waktu reaksi dan persen katalis terhadap kemurnian biodiesel dapat dilihat pada gambar 2 .

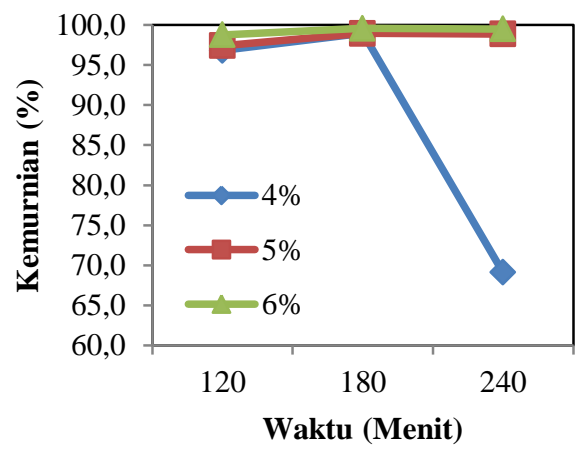

Gambar 2. Hubungan antara Waktu Reaksi dan Persen Katalis terhadap Kemurnian Biodiesel

Hasil penelitian ini dimana pada katalis $6 \%$ kemurnian meningkat seiring bertambahnya waktu reaksi dari 2 jam ke 3 jam yaitu dari 98,76 menjadi 99,58\% akan tetapi menurun pada waktu reaksi 4 jam yaitu 99,49\%. Waktu reaksi yang semakin banyak akan mengurangi kemurnian dari biodiesel yang dihasilkan. Hal ini di karenakan apabila kesetimbangan reaksi sudah tercapai maka kemurnian akan semakin berkurang.

\section{Pengaruh Waktu Reaksi dan Persen Katalis Terhadap Densitas Biodiesel}

Hubungan pengaruh waktu reaksi dan persen katalis terhadap densitas biodiesel dapat dilihat pada gambar 3 berikut. 


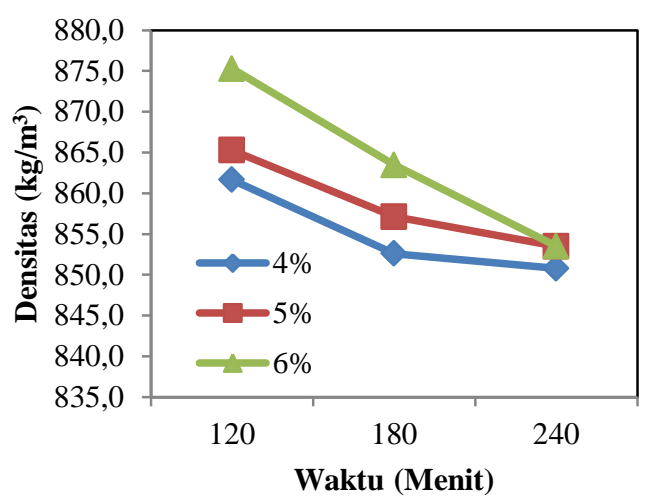

Gambar 3. Hubungan antara Waktu Reaksi dan Persen Katalis terhadap Densitas Biodiesel

Menurut Standar Nasional Indonesia (SNI 04-7182-2012) [14], densitas biodiesel pada suhu $40{ }^{\circ} \mathrm{C}$ adalah $850-890 \mathrm{~kg} / \mathrm{m}^{3}$. Dari hasil penelitian untuk berbagai variasi yang dilakukan diperoleh densitas berkisar 850-880 $\mathrm{kg} / \mathrm{m}^{3}$. Dengan demikian biodiesel yang diperoleh telah memenuhi standar densitas biodiesel.

\section{Pengaruh Waktu Reaksi dan Persen Katalis Terhadap Viskositas Biodiesel}

Hubungan pengaruh waktu reaksi dan persen katalis terhadap viskositas biodiesel dapat dilihat pada gambar 4 .

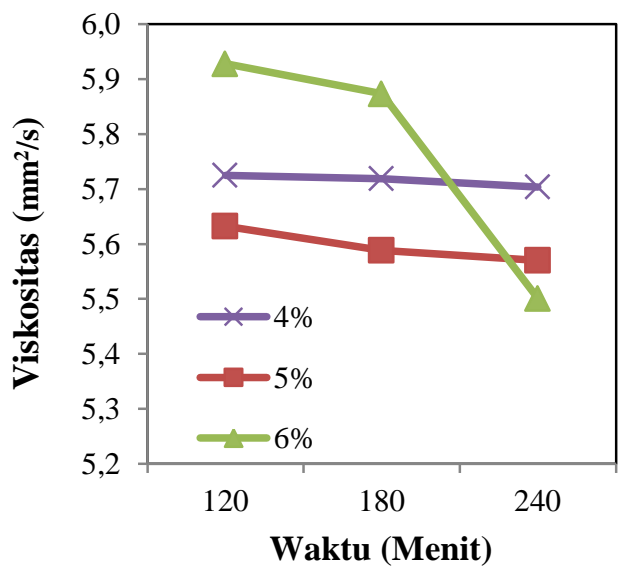

Gambar 4. Hubungan antara Waktu Reaksi dan Persen katalis terhadap Viskositas Kinematik Biodiesel

Pada gambar 4 dapat dilihat bahwa semakin lama waktu reaksi yang digunakan maka viskositas kinematik yang dihasilkan akan semakin rendah. Menurut Standar Nasional Indonesia (SNI 04-7182-2012) [14], viskositas kinematik biodiesel pada suhu $40{ }^{\circ} \mathrm{C}$ adalah 2,3-
$6,0 \mathrm{~mm}^{2} / \mathrm{s}$. Dari hasil penelitian untuk berbagai variasi yang dilakukan diperoleh viskositas kinematik berkisar $5,0-6,0 \mathrm{~mm} / \mathrm{s}$. Dengan demikian biodiesel yang diperoleh telah memenuhi standar viskositas kinematik biodiesel.

\section{Kesimpulan}

1. Proses pretreatment pemurnian minyak jelantah menggunakan karbon aktif menurunkan kadar FFA sebesar 73,80\%.

2. Kulit kakao digunakan sebagai katalis biodiesel dengan memanfaatkan kandungan $\mathrm{K}_{2} \mathrm{O}$ yang terkandung dalam abu kulit kakao yang kalsinasi pada temperatur $650^{\circ} \mathrm{C}$ sebesar $45,13 \%$.

3. Hasil kemurnian dan yield metil ester yang tertinggi adalah 99,5874 \% dan 92,68 diperoleh pada suhu operasi $65{ }^{\circ} \mathrm{C}$ dengan persen katalis $6 \%$, rasio molar metanol : WCO sebesar 12:1 selama 3 jam sehingga telah memenuhi syarat standard biodiesel yang harus mencapai $>96,5 \%$.

4. Densitas metil ester yang dihasilkan 850$875 \mathrm{~kg} / \mathrm{m}^{3}$ dan viskositas kinematik metil ester yang dihasilkan 5,0-6,0 $\mathrm{mm}^{2} / \mathrm{s}(\mathrm{cSt})$

\section{Daftar Pustaka}

[1] B. A. Bilgin., Mert Gülüm, İhsan Koyuncuoglu, Elif Nac, and Abdülvahap Cakmak, Determination of Transesterification Reaction Parameters Giving the Lowest Viscosity Waste Cooking Oil Biodiesel. Procedia - Social and Behavioral Sciences, 195 : $2492-$ 2500. 2015.

[2] C. Ofori-Boateng, and Keat Teong Lee, The potential of using cocoa pod husks as green solid base catalysts for the transesterification of soybean oil into biodiesel: Effects of biodiesel on engine performance. School of Chemical Engineering, University Sains Malaysia. 2013.

[3] F. I. Darmawan, dan I Wayan Susila, Proses Produksi Biodiesel dari Minyak Jelantah dengan Metode Pencucian DryWash Sistem. Jurusan Teknik Mesin, Fakultas Teknik, Surabaya: Universitas Negeri Surabaya. JTM. Volume 02 Nomor $01: 80$ - 87. 2013.

[4] Hanif, Analisis Sifat Fisik dan Kimia Biodiesel dari Minyak Jelantah sebagai Bahan Bakar Alternatif Motor Diesel. Jurusan Teknik Mesin Politeknik, Negeri Padang. 2009.

[5] I. W. Sutapan dan Rosmawaty, Pengaruh Berat Katalis, Suhu Dan Waktu Reaksi 
Terhadap Produk Biodiesel Dari Lemak Sapi. Jurusan Kimia, Fakultas Matematika dan Ilmu Pengetahuan Alam, Ambon : Universitas Pattimura. Seminar Nasional Basic Science VI. 2014.

[6] MSDS, Metanol. Terra Nitrogen Corporation. 2016.

[7] M. Sinaga, dkk, The Produce Methyl Ester From Crude Palm Oil use Chikken bones Ash as Catalyst. Annual Applied Since and Engineering Converence. Bandung. 2016.

[8] Mhd. Zalukhu, Pembuatan Biodiesel dari Minyak Kelapa Sawit dengan Menggunakan Katalis $\mathrm{CaO}$ dengan Proses Transesterifikasi. http://respository.unri.ac.id. 2011.

[9] O. S. Stamenkovic'., Ana V. Velic`kovic', and Vlada B. Veljkovic', The production of biodiesel from vegetable oils by ethanolysis: Current state and perspectives. Fuel 90 : 31413155. 2011.

[10] R. Jannah, Reaksi Transesterifikasi Trigliserida Minyak Jarak Pagar dengan Metanol menggunakan Katalis Padatan Basa $\mathrm{K}_{2} \mathrm{CO}_{3} / \mathrm{y}-\mathrm{Al}_{2} \mathrm{O}_{3}$. Departemen Kimia. FMIPA. Depok : Universitas Indonesia. 2008.

[11] R. S. Putra., Tatang Shabur Julianto, Puji Hartono, Ratih Dyah Puspitasari, and Angga Kurniawan, Pre-treatment of Used-Cooking Oil as Feed Stocks of Biodiesel Production by using Activated Carbon and Clay Minerals. Int. Journal of Renewable Energy Development 3 (1) : 33-35. 2014.

[12] S. F. Haryono, Yavita Sari, Ika Rakhmawati, Pengolahan Minyak Goreng Kelapa Sawit Bekas menjadi Biodiesel Studi Kasus: Minyak Goreng Bekas dari KFC Dago Bandung. Prosiding Seminar Nasional Teknik Kimia. ISSN 1693 - 4393. Jurusan Teknik Kimia, Bandung : Institut Teknologi Nasional. 2010

[13] Sirisomboonchai, dkk, Biodiesel production from waste cooking oil using calcined scallop shell as catalyst. Energy conversion and management, 95 : 242247. 2015.

[14] Standar Nasional Indonesia, www.bsn.com, SNI : 7182:2012, 2012, diakses pada 28 Juli 2016.

[15] S. H. Syamsidar, Pembuatan dan Uji Kualitas Biodiesel dari Minyak Jelantah. Jurusan Kimia, Fakultas Sains dan
Teknologi, Makassar : UIN Alauddin Makassar. 2010.

[16] T. Marnoto dan Abdullah Efendi, Biodiesel dari Lemak Hewani (Ayam Broiler) dengan Katalis Kapur Tohor. Jurusan Teknik Kimia. Fakultas Teknologi Industri. Yogyakarta : Universitas Pembangunan Nasional "Veteran". Prosiding Seminar Nasional Teknik Kimia "Kejuangan" Pengembangan Teknologi Kimia untuk Pengolahan Sumber Daya Alam Indonesia. ISSN 1693 - 4393. 2011.

[17] W. Zhu., Zhi-Min Zong, Hong-Lei Yan, Yun-Peng Zhao, Yao Lu, Xian Yong Wei, dan Dongke Zhang, Cornstalk Liquefaction in Metanol/Water Mixed Solvents. Fuel Processing Technology. Vol 117:1-7. 2014.

[18] Z. Z. Cai., Yong Wang, Ying-Tai Tang, Ka-Man Chong, Jia- Wei Wang, Jie-Wen Zhang, De Po Yang. A Two-Step Biodiesel Production Process from Waste Cooking Oil via Recycling Crude Glycerol Esterification Catalyzed by Alkali Catayst. Fuel Processing Technology, 137 : 186-193. 2015. 